\title{
Conhecimentos, atitudes e percepção de risco dos acadêmicos de Fonoaudiologia perante a AIDS
}

Knowledge, attitudes and risk perception of fonoaudiologia students regarding AIDS

Conocimientos, Actitudes y percepción del riesgo de académicos de la Fonoaudiología ante el SIDA

\author{
Pamela Staliano* \\ Angela Elizabeth Lapa Coêlho**
}

\begin{abstract}
Resumo
O objetivo desta pesquisa foi avaliar o conhecimento, atitudes e percepção de risco dos acadêmicos do Curso de Fonoaudiologia de uma universidade particular do Município de Campo Grande, MS, frente a AIDS. Cento e trinta e sete acadêmicos responderam a um questionário estruturado. Os participantes demonstraram um relevante conhecimento sobre a identidade do HIV e sobre os meios de transmissão, porém o mesmo não aconteceu com o conhecimento sobre as medidas preventivas da transmissão sexual. Também foram identificadas certas atitudes negativas frente ao atendimento de portadores do HIV/AIDS, fato esse que poderá repercutir na sua forma de lidar com essas pessoas. Outro dado preocupante foi que a maioria afirmou não correr risco de pegar a AIDS. Os alunos relataram ainda que se sentem despreparados para intervirem na problemática em questão, necessitando de maior capacitação profissional.
\end{abstract}

Palavras-chave: AIDS; atitudes; conhecimentos; percepção de risco.

\begin{abstract}
The objective of this research was to evaluate the knowledge, attitudes and perception of risk of the academics of the Course of Fonoaudiologia at a particular university regarding AIDS. One hundred and thirty seven academics answered a structured questionnaire. The participants had demonstrated an excellent knowledge about the identity of the HIV and the ways of transmission, however the same did not happen with the knowledge about prevention related to sexual transmission. Also,
\end{abstract}

\footnotetext{
Doutoranda do Programa de Pós-graduação em Processos de Desenvolvimento Humano e Saúde (PG-PDS) da Universidade de Brasília (UnB), bolsista do CAPES. Endereço para correspondência: Avenida Afonso Pena, 1557, Bloco A, apto 307, Centro, Campo Grande-MS. CEP: 79002-070. Telefones: (67) 9231-8021 e 8174-4031. E-mails: pamelastaliano@ hotmail.com,pamela@unb.br.

** Prof. ${ }^{a}$ Dr. ${ }^{a}$ do Centro Universitário de João Pessoa - Unipê. E-mail: angelacoelho1@gmail.com.
} 
certain negative attitudes had been identified regarding care of people with HIV/AIDS, fact that might interfere in the way they take care of these people. Another preoccupying data were that the majority affirmed not to be at risk to get AIDS. The students told that they felt unprepared to work within this area, and they needed more professional training.

Keywords: AIDS; attitudes; knowledge; risk perception.

\section{Resumen}

El objetivo de este estudio fue evaluar los conocimientos, actitudes y percepción de riesgo de los académicos de la Fonoaudiología en una universidad privada en la ciudad de Campo Grande, MS, en comparación con SIDA. Ciento treinta y siete estudiantes respondieron a un cuestionario estructurado. Los participantes demostraron un conocimiento significativo sobre la identidad del HIV y los medios de transmisión, pero lo mismo no era el verdadero conocimiento acerca de las medidas de prevención de la transmisión sexual. También puso de relieve algunas actitudes negativas en contra de la atención del HIV / SIDA, un hecho que puede reflejar con el fin de cumplir con estas personas. Otro hecho preocupante que la mayoría dijo que no estaba en riesgo de contraer SIDA. Los estudiantes también señalan que no se sienten preparados para intervenir en el asunto en cuestión, que requieren una mayor formación profesional.

Palabras clave: SIDA; actitudes; conocimientos; percepción del riesgo.

\section{Introdução}

Cegundo o Ministério da Saúde (Brasil, 2009), existem hoje, aproximadamente, 33,4 milhões de pessoas infectadas pelo vírus da AIDS. No Brasil, de 1980 a junho de 2009, foram notificados 544846 casos e constatados 217091 óbitos até 2009, entre os quais se encontram muitos jovens na faixa etária que compreende o final da adolescência e o início da vida adulta. Esses números são dados da Organização Mundial de Saúde (OMS) e sugerem que, no mundo, quase a metade de todos os infectados pelo HIV tem menos de 25 anos de idade. Em Mato Grosso do Sul, o número de casos notificados até junho de 2009, de acordo com o Ministério da Saúde, é de 6 039, ocupando o sétimo lugar em incidência de casos no Brasil. Em Campo Grande, existem 3002 casos notificados, o que corresponde a quase $50 \%$ dos casos existentes no Estado. 


\section{Medidas preventivas}

Dados do Ministério da Saúde apontam que o Brasil pode ser considerado referência mundial na pesquisa de medicamentos de combate à AIDS, porém, em alguns casos, o mesmo não acontece quanto à prevenção. E é justamente por esse fato que inúmeras universidades estão se preocupando com essa questão, pois como a AIDS não tem cura, é fundamental a elaboração de estratégias educativas/preventivas direcionadas à informação, esclarecimento e desenvolvimento de habilidades que atuem na mudança de comportamento (Hallack Neto et alii, 1996; Toledo Júnior et alii, 1999; Camargo \& Ferrari, 2009). Diante da expansão da doença e da falta de uma vacina eficaz com a possibilidade imediata de utilização, a prevenção ainda se apresenta como a principal arma no combate à doença (Gimenez et alii, 1996; Madureira \& Trentini, 2008).

Outro fator preocupante que está chamando a atenção de pesquisadores e os levando a desenvolver programas preventivos é o entendimento inadequado, tanto com relação à transmissão do HIV quanto às medidas preventivas contra o HIV entre os universitários. Gir et alii (1999) apontam que o número de estudantes que relatou adotar medidas preventivas corretas para a AIDS e DSTs foi bem abaixo do esperado.

Já os resultados mencionados no estudo de Hallack Neto et alii (1996) mostram que os universitários ainda apresentam dúvidas sobre AIDS que podem refletir no seu comportamento social, o que propicia o surgimento de preconceitos e riscos de infecção. Martins et alii (2006) identificaram que existem alguns fatores associados ao conhecimento adequado sobre prevenção de DSTs/AIDS, tais como: ter maior nível de escolaridade, ser do sexo feminino, estudar em escola privada e ser solteiro.

\section{Atitudes e conhecimento}

A temática das atitudes merece ser discutida, pois, entre o saber e o fazer, há uma série de fatores que influenciam o comportamento, entre os quais estão as atitudes, que geram discussóes quanto a suas definição, formação e mudança de atitudes e ainda, como as atitudes, por sua vez, influenciam o comportamento de uma pessoa. Com relação a essa questão, cabe citar as crenças pessoais e as normas sociais da pessoa em questão (Rodrigues, 2005).

O conhecimento não implica necessariamente mudança de comportamento que demonstre respostas favoráveis de prevenção à AIDS. Andrade e Tanaka (2002, p. 65-66) abordam representações de profissionais de saúde que 
trabalham com HIV/AIDS, demonstrando que mesmo tais profissionais que têm todo tipo de conhecimento sobre a doença relatam atitudes não condizentes com seu conhecimento, como:

temos uma bagagem teórica que propicia conhecer todas as possibilidades de risco. Só que antes de ser profissional de saúde, nós somos seres humanos, com todas as dificuldades, com todos os erros e fantasias.... Parece que, na vida pessoal, somos iguais aos pacientes, pensamos que estamos longe da AIDS.... Uma coisa é certa: o fato de ter conhecimento não favorece a proteção. Não existe essa relação entre o conhecimento e a vida. Muda somente a consciência.

Dessa forma, as atitudes positivas não se relacionam apenas com a história de vida das pessoas, mas com seu ambiente social e relacional, assim como com as necessidades com as quais se confrontam.

Certamente as mudanças comportamentais acontecem conforme as pessoas se percebem sob o risco de adquirir o vírus. McCornick (1997), em seu estudo baseado na mudança de conhecimentos e atitudes de estudantes universitários sobre HIV/AIDS, num período de oito anos, identificou um grande conhecimento sobre HIV/AIDS por parte desses universitários, porém há alguns erros que persistiram sobre os sintomas, transmissão e prognóstico dos pacientes. No entanto, de acordo com os dados, o medo dos pacientes e a hostilidade para com os homossexuais com HIV diminuíram durante estes oito anos. $\mathrm{O}$ autor afirma ainda que, embora a percepção pessoal do risco seja a primeira variável da mudança nas práticas sexuais, as estratégias universitárias para intervirem nessa mudança devem ser adequadas.

Outro estudo que salienta a necessidade de levar em consideração as condições biopsicossociais e culturais das pessoas na adoção de estratégias preventivas foi realizado por Almeida, Silva e Cunha (2007), e teve como objetivo identificar e comparar os conhecimentos, atitudes e comportamentos preventivos sobre AIDS de adolescentes das áreas urbana e rural. Os resultados revelaram que o meio em que os adolescentes vivem influenciou as respostas sobre o conhecimento da AIDS como uma doença grave, bem como sobre os riscos de transmissão. Os adolescentes da área rural demonstraram mais conhecimento quanto às atitudes preventivas em relação à AIDS, enquanto os adolescentes da área urbana demonstram comportamentos de risco e menos atitudes preventivas.

Em relação às ações preventivas, os autores Camargo e Botelho (2007) argumentam que um dos grandes obstáculos dessas medidas, em muitos 
países, inclusive no Brasil, consiste no fato de as políticas públicas não levarem em consideração a cultura sexual das populações. Esse fato gera preocupação, uma vez que a adoção de medidas preventivas, em especial o uso de preservativo, é um comportamento complexo que compreende tanto valores e crenças como aspectos afetivos e sexuais. Os autores complementam, afirmando que o desconhecimento dos riscos, a desinformação e a falta de programas de prevenção na maioria das escolas brasileiras constituem-se fatores promotores do aumento de adolescentes portadores de HIV.

Madureira e Trentini (2008) apontam que antes mesmo de se propor estratégias preventivas frente à DSTs/AIDS, faz-se necessário conhecer os aspectos relacionados às crenças, aos mitos, aos estereótipos em saúde, aos saberes de cada um, às questões de gênero e às características dos relacionamentos conjugais e ou extraconjugais, uma vez que o sexo seguro e a prevenção de doenças não estão diretamente ligados ao uso do preservativo, mas à confiança, à cumplicidade, à fidelidade, ao diálogo, ao companheirismo existente no casal e à qualidade da vida sexual. Ou seja, a opção de utilizar ou não medidas preventivas nas relações sexuais não é apenas uma questão normatizada cientificamente, mas fundamentada por comportamentos.

Alguns fatores foram considerados na escolha de universitários para participar desta pesquisa. Em primeiro lugar, a universidade conta com um grande número de alunos jovens, que estão incluídos na faixa etária na qual há maior incidência de casos de AIDS. Em segundo lugar, os alunos, na sua maioria, estão em plena fase de atividade sexual. E, finalmente, os acadêmicos de Fonoaudiologia, provavelmente, quando estiverem desenvolvendo suas atividades profissionais, virão a atender indivíduos portadores do HIV ou com AIDS plenamente manifesta. Por essas razões, há interesse na pesquisa sobre conhecimentos, atitudes e percepção de risco a respeito dessa síndrome, para que se possa desenvolver um plano de intervenção no futuro.

\section{Método}

\section{Participantes}

Participaram da pesquisa 137 acadêmicos dos quatro anos do curso de Fonoaudiologia de uma universidade particular da região Centro-Oeste, sendo 50 acadêmicos do primeiro ano, 21 do segundo ano, 26 do terceiro ano e 40 do quarto ano. 


\section{Instrumento}

Utilizou-se um questionário estruturado, com perguntas abertas e fechadas. O questionário foi baseado em pesquisas anteriores (Diclemente, Zorn \& Temoshok, 1986; Owens, 1995) e foi modificado e adaptado ao nosso públicoalvo. As questôes se dividiram em sete seções: (1) 4 perguntas abertas, cujo intuito era investigar se os participantes haviam participado de algum curso ou palestra sobre AIDS; (2) seção referente à identidade do HIV, formas de contaminação e tratamento da doença, com dez itens em formato Likert; (3) 11 itens em formato Likert, versando sobre o conhecimento sobre as medidas preventivas; (4) 21 itens, todos em formato Likert, relacionados com as atitudes perante a AIDS; (5) 18 itens referentes às percepções de risco diante da AIDS, também em formato Likert; (6) nessa seção, buscou-se investigar se os participantes sentiam necessidade de receber mais instruçôes ou treinamento sobre a AIDS e ainda a quem recorreriam para receber tais informações; (7) a última seção foi constituída de quatro questôes sobre os dados demográficos dos participantes.

\section{Procedimento}

Para iniciar a coleta de dados, primeiramente se procurou a coordenadora do curso de Fonoaudiologia, para informá-la da aplicação dos questionários. Posteriormente, foram contatados os professores do respectivo curso, com os quais se discutiram os melhores horários e dias para a aplicação dos questionários. A participação dos acadêmicos foi estritamente voluntária, e eles ficaram livres para deixar de responder o questionário, a qualquer momento.

Foi utilizado o programa estatístico Statistical Package for Social Sciences (SPSS). Depois de codificados e conferidos, os dados dos questionários foram inseridos e novamente conferidos para a eliminação de erros de digitação. Em seguida, foram realizadas as análises descritivas de todas as variáveis.

A pesquisa obedeceu à Resolução 196/1996 da Comissão Nacional de Ética em Pesquisa (Conep), e foi aprovada por Comitê de Ética em Pesquisa reconhecido.

\section{Resultados e discussão}

A média de idade da população foi de 22,15 anos, era predominantemente feminina, com 126 mulheres (92\%) e 11 homens (8\%). A amostra estudada continha alunos dos quatro anos do curso de Fonoaudiologia, sendo 50 (36,5\%) acadêmicos do primeiro ano, 21 (15,3\%) do segundo ano, 26 (19\%) do terceiro ano e $40(29,2 \%)$ do quarto ano. Essa amostra representa $80,6 \%$ do total de estudantes. 
Pouco mais da metade dos participantes $(51,8 \%)$ relataram ter participado de alguma palestra, treinamento e ou curso sobre AIDS. A maioria participou entre 1998 a 2002, ou seja, dos 30\% que especificaram o ano e o local de realização, $27 \%$ o realizaram nesse período, com o máximo de 40 horas e uma média de aproximadamente 7 horas de participação. A escola aparece como a maior provedora dessas participações, com $27,7 \%$.

\section{Conhecimentos}

$\mathrm{Na}$ tabela 1, estão apresentados os dados referentes ao conhecimento relatado pelos participantes sobre a AIDS no que se refere à identidade do vírus, às características físicas do contaminado e às formas de tratamento para a doença. Com o intuito de facilitar a observação e apresentação dos resultados, as categorias de respostas "definitivamente verdadeira" e "provavelmente verdadeira" foram agrupadas em uma só categoria "verdadeira". O mesmo foi feito com as categorias "provavelmente falso" e "definitivamente falso", na categoria "falso".

Tabela 1 - Conhecimento relatado pelos acadêmicos sobre a identidade do HIV, características do contaminado e tratamento da doença

\begin{tabular}{|c|c|c|c|c|c|c|c|c|}
\hline \multirow[t]{2}{*}{ Questões/categorias das respostas } & \multicolumn{2}{|c|}{ Verdadeiro } & \multicolumn{2}{|c|}{ Falso } & \multicolumn{2}{|c|}{ Não sei } & \multicolumn{2}{|c|}{$\begin{array}{l}\text { Não } \\
\text { resp. }\end{array}$} \\
\hline & $\mathrm{n}$ & $\%$ & $\mathrm{n}$ & $\%$ & $\mathrm{n}$ & $\%$ & $\mathrm{n}$ & $\%$ \\
\hline $\begin{array}{l}\text { 1. Uma pessoa pode ser contaminada } \\
\text { pelo HIV sem saber }\end{array}$ & 113 & 82,5 & 13 & 9,5 & 5 & 3,6 & 6 & 4,4 \\
\hline $\begin{array}{l}\text { 2. Uma pessoa pode estar contaminada } \\
\text { pelo HIV sem se sentir doente }\end{array}$ & 111 & 81 & 11 & 8,0 & 9 & 6,6 & 6 & 4,4 \\
\hline $\begin{array}{l}\text { 3. Uma pessoa que se sente saudável } \\
\text { pode transmitir o HIV }\end{array}$ & 111 & 81 & 10 & 7,3 & 7 & 5,1 & 9 & 6,6 \\
\hline $\begin{array}{l}\text { 4. A AIDS pode ser curada se tratada no } \\
\text { início }\end{array}$ & 22 & 16 & 97 & 70,8 & 9 & 6,6 & 9 & 6,6 \\
\hline $\begin{array}{l}\text { 5. No ambiente de instituições de saúde, } \\
\text { deve-se considerar todos os pacientes } \\
\text { como potencialmente portadores do HIV }\end{array}$ & 47 & 34,3 & 64 & 46,7 & 20 & 14,6 & 6 & 4,4 \\
\hline 6. Qualquer pessoa pode pegar AIDS & 122 & 89,1 & 5 & 3,6 & 4 & 2,9 & 6 & 4,4 \\
\hline 7. A AIDS é transmitida por um vírus & 118 & 86,1 & 10 & 7,3 & 4 & 2,9 & 5 & 3,6 \\
\hline 8. Não existe vacina contra a AIDS & 91 & 66,4 & 33 & 24,1 & 8 & 5,8 & 5 & 3,6 \\
\hline $\begin{array}{l}\text { 9. Tanto os homens quanto as mulheres } \\
\text { podem transmitir o HIV }\end{array}$ & 123 & 89,8 & - & - & 7 & 5,1 & 7 & 5,0 \\
\hline $\begin{array}{l}\text { 10. Eu saberia se uma pessoa tem o HIV } \\
\text { só pela aparência. }\end{array}$ & 10 & 7,2 & 120 & 87,6 & 3 & 2,2 & 4 & 3,0 \\
\hline
\end{tabular}

Fonte: dados da pesquisa. 
Os estudantes apresentaram, no geral, respostas adequadas em relação à identidade do vírus. Porém há algumas questôes com índices relevantes de respostas erradas, como, por exemplo, 24,1\% dos alunos acreditam que existe vacina contra a AIDS e 16\% acreditam que a AIDS pode ser curada, se tratada no início. Houve ainda um percentual de $46,7 \%$ dos participantes afirmando que, em instituições de saúde, nem todas as pessoas devem ser tratadas como possíveis portadores do vírus HIV. Em se tratando de acadêmicos da área da saúde, isso se torna preocupante, uma vez que eles devem ser orientados sobre questôes de biossegurança em ambientes e instituiçóes de saúde. Com essa porcentagem de respostas desse cunho, acredita-se que essa orientação não vem sendo dada.

Pode-se notar que o nível de conhecimento sobre as formas de prevenção não é tão satisfatório quanto o conhecimento sobre características do contaminado, etiologia da doença e seu tratamento demonstrado na tabela anterior. Os participantes denotam muitas dúvidas referentes às medidas preventivas contra o vírus HIV. Não souberam dizer ao certo qual a eficácia dos métodos elencados no questionário, como se pode observar na tabela 2, em que as categorias de resposta "nada eficaz" e "pouco eficaz" foram agrupadas na categoria "não eficaz".

Tabela 2 - Conhecimento revelado pelos acadêmicos sobre as medidas preventivas da transmissão sexual do HIV/AIDS.

\begin{tabular}{|c|c|c|c|c|c|c|c|c|}
\hline \multirow{2}{*}{$\begin{array}{l}\text { Questões/categoria das } \\
\text { respostas }\end{array}$} & \multicolumn{2}{|c|}{ Não sei } & \multicolumn{2}{|c|}{ Não eficaz } & \multicolumn{2}{|c|}{ Eficaz } & \multicolumn{2}{|c|}{ Não Resp } \\
\hline & $\underline{\mathrm{n}}$ & $\%$ & $\underline{\mathrm{n}}$ & $\%$ & $\underline{\mathrm{n}}$ & $\%$ & $\underline{\mathrm{n}}$ & $\%$ \\
\hline 1. Usar diafragma & 24 & 17,5 & 103 & 75,2 & 6 & 4,4 & 4 & 3,0 \\
\hline $\begin{array}{l}\text { 2. Usar camisinha feita de } \\
\text { látex }\end{array}$ & 6 & 4,4 & 28 & 20,5 & 99 & 72,3 & 4 & 3,0 \\
\hline $\begin{array}{l}\text { 3. Usar geleia espermicida, } \\
\text { espuma ou creme }\end{array}$ & 13 & 9,5 & 118 & 86,1 & 2 & 1,5 & 4 & 3,0 \\
\hline $\begin{array}{l}\text { 4. Usar a pílula anticoncep- } \\
\text { cional }\end{array}$ & 2 & 1,5 & 130 & 94,9 & 1 & 0,7 & 4 & 3,0 \\
\hline 5. Usar o coito interrompido & 18 & 13,1 & 116 & 84,7 & - & - & 2 & 1,5 \\
\hline 6. Fazer vasectomia & 15 & 10,9 & 116 & 84,6 & 3 & 2,2 & 3 & 2,2 \\
\hline $\begin{array}{l}\text { 7. Ter relação sexual vaginal } \\
\text { com a camisinha }\end{array}$ & 6 & 4,4 & 31 & 21,6 & 97 & 70,8 & 3 & 2,2 \\
\hline $\begin{array}{l}\text { 8. Ter relação sexual oral com } \\
\text { a camisinha }\end{array}$ & 8 & 5,8 & 30 & 21,9 & 95 & 69,3 & 4 & 3,0 \\
\hline
\end{tabular}




\begin{tabular}{lccccccccc}
\hline $\begin{array}{l}\text { Questões/categoria das } \\
\text { respostas }\end{array}$ & \multicolumn{2}{c}{ Não sei } & \multicolumn{2}{c}{ Não eficaz } & \multicolumn{2}{c}{ Eficaz } & \multicolumn{2}{c}{ Não Resp. } \\
& $\underline{\mathrm{n}}$ & $\%$ & $\underline{\mathrm{n}}$ & $\%$ & $\underline{\mathrm{n}}$ & $\%$ & $\underline{\mathrm{n}}$ & $\%$ \\
\hline $\begin{array}{l}\text { 9. Ter relação sexual anal } \\
\text { com a camisinha }\end{array}$ & 6 & 4,4 & 29 & 21,1 & 95 & 69,3 & 7 & 5,0 \\
$\begin{array}{l}\text { 10. Evitar relações sexuais } \\
\text { com profissionais do sexo }\end{array}$ & 7 & 5,1 & 47 & 34,3 & 78 & 56,9 & 5 & 3,6 \\
sem camisinha & & & & & & & & \\
$\begin{array}{l}\text { 11. Conhecer a história sexu- } \\
\text { al do(a) parceiro(a) }\end{array}$ & 3 & 2,2 & 72 & 52,6 & 60 & 43,8 & 2 & 1,5 \\
\hline
\end{tabular}

Fonte: dados da pesquisa.

No que diz respeito às medidas preventivas utilizadas para impedir a contaminação pelo HIV através da relação sexual, os participantes revelaram certo desconhecimento quanto à eficácia dos métodos citados, como, por exemplo, o uso do diafragma $(17,5 \%)$, do coito interrompido $(13,1 \%)$, da vasectomia $(10,9 \%)$ e da geleia espermicida, espuma ou creme $(9,5 \%)$.

Considerando que a prevenção deve ser priorizada quando se espera a diminuição da incidência e ou prevalência de doenças, o conhecimento sobre a AIDS é um fator importante par a prevenção da doença. Mesmo que a mídia, por meio de campanhas, priorize informações sobre os meios de transmissão sexual da AIDS, nota-se que os universitários demonstram desconhecimento considerável em relação a essas questôes tão propagadas pela mídia.

Outro dado preocupante a ser discutido é a porcentagem de alunos $(43,8 \%)$ que acredita ser eficaz conhecer a história sexual do parceiro para se prevenir contra a AIDS, caracterizando o que Camargo e Botelho (2007) sinalizam por sentimento de vulnerabilidade pessoal, ou seja, conhecer a história sexual do parceiro leva os alunos a pensar que estão protegidos contra a AIDS e que não precisam negociar o uso do preservativo com seus companheiros, o que representa uma dificuldade bastante evidente em pesquisas (Camargo \& Botelho, 2007; Martins et alii, 2006; Madureira \& Trentini, 2008).

Os resultados relacionados com o comportamento dos estudantes perante a AIDS estão explicitados na tabela 3. As categorias de respostas "muito provável" e "provável" foram agrupadas em uma só, bem como as categorias "pouco provável” e "improvável". 
Tabela 3 - Conhecimento revelado pelos acadêmicos sobre os meios de transmissão do HIV/AIDS.

\begin{tabular}{|c|c|c|c|c|c|c|c|c|}
\hline \multirow{2}{*}{ Questões/categoria das respostas } & \multicolumn{2}{|c|}{ Provável } & \multicolumn{2}{|c|}{ Improvável } & \multicolumn{2}{|c|}{ Não Sei } & \multicolumn{2}{|c|}{ Não Resp. } \\
\hline & $\underline{\mathrm{n}}$ & $\%$ & $\underline{\mathrm{n}}$ & $\%$ & $\underline{\mathrm{n}}$ & $\%$ & $\underline{\mathrm{n}}$ & $\%$ \\
\hline $\begin{array}{l}\text { 1. Apertar a mão, tocar ou beijar o } \\
\text { rosto de uma pessoa que é porta- } \\
\text { dora do HIV }\end{array}$ & 1 & 0,6 & 133 & 97,3 & - & - & 3 & 2,1 \\
\hline $\begin{array}{l}\text { 2. Frequentar uma escola com um } \\
\text { aluno que tem o HIV }\end{array}$ & 1 & 0,6 & 133 & 97,3 & - & - & 3 & 2,1 \\
\hline $\begin{array}{l}\text { 3. Morar próximo a um hospital ou } \\
\text { abrigo de pessoas vivendo com HIV/ } \\
\text { AIDS }\end{array}$ & 2 & 1,5 & 129 & 94,3 & 1 & 0,6 & 5 & 3,6 \\
\hline $\begin{array}{l}\text { 4. Trabalhar com uma pessoa que é } \\
\text { portadora do HIV }\end{array}$ & 2 & 1,5 & 130 & 94,9 & 1 & 0,6 & 4 & 3,0 \\
\hline $\begin{array}{l}\text { 5. Compartilhar pratos, garfos, ou } \\
\text { copos com uma pessoa que é porta- } \\
\text { dora do HIV }\end{array}$ & 11 & 8,0 & 116 & 84,6 & 6 & 4,4 & 4 & 3,0 \\
\hline $\begin{array}{l}\text { 6. Ser atingido por tosse ou espirro } \\
\text { de uma pessoa que é portadora do } \\
\text { HIV }\end{array}$ & 13 & 9,5 & 108 & 78,8 & 12 & 8,7 & 4 & 3,0 \\
\hline 7. Usar banheiros públicos & 15 & 11,1 & 109 & 79,5 & 10 & 7,3 & 3 & 2,1 \\
\hline $\begin{array}{l}\text { 8. Ser picado por mosquito ou ou- } \\
\text { tros insetos }\end{array}$ & 12 & 8,7 & 109 & 79,5 & 13 & 9,5 & 3 & 2,1 \\
\hline $\begin{array}{l}\text { 9. Ter cabelos ou unhas cortadas por } \\
\text { uma pessoa que é portadora do HIV }\end{array}$ & 12 & 8,7 & 111 & 79,3 & 6 & 4,4 & 9 & 6,6 \\
\hline $\begin{array}{l}\text { 10. Beijar na boca uma pessoa que é } \\
\text { portadora do HIV }\end{array}$ & 40 & 29,2 & 86 & 62,8 & 6 & 4,4 & 5 & 3,6 \\
\hline $\begin{array}{l}\text { 11. Ter contato com o suor de uma } \\
\text { pessoa que é portadora do HIV }\end{array}$ & 11 & 8,0 & 115 & 84,0 & 4 & 3,0 & 7 & 5,0 \\
\hline 12. Doar sangue & 70 & 50,1 & 64 & 46,8 & - & - & 3 & 2,1 \\
\hline $\begin{array}{l}\text { 13. Ter nascido de uma mãe que é } \\
\text { portadora do HIV }\end{array}$ & 113 & 82,5 & 19 & 13,9 & - & - & 5 & 3,6 \\
\hline $\begin{array}{l}\text { 14. Ter contato com as lágrimas de } \\
\text { uma pessoa que é portadora do HIV }\end{array}$ & 13 & 9,5 & 107 & 78,2 & 7 & 5,0 & 10 & 7,3 \\
\hline $\begin{array}{l}\text { 15. Receber uma transfusão de san- } \\
\text { gue contaminado }\end{array}$ & 129 & 94,2 & 5 & 3,7 & - & - & 3 & 2,1 \\
\hline $\begin{array}{l}\text { 16. Compartilhar agulhas com usuá- } \\
\text { rios de drogas injetáveis }\end{array}$ & 132 & 96,4 & 1 & 0,6 & - & - & 4 & 3,0 \\
\hline $\begin{array}{l}\text { 17. Ter relações sexuais com profis- } \\
\text { sionais do sexo sem usar a camisinha }\end{array}$ & 135 & 99,5 & - & - & - & - & 2 & 1,5 \\
\hline
\end{tabular}




\begin{tabular}{|c|c|c|c|c|c|c|c|c|}
\hline \multirow{2}{*}{ Questões/categoria das respostas } & \multicolumn{2}{|c|}{ Provável } & \multicolumn{2}{|c|}{ Improvável } & \multicolumn{2}{|c|}{ Não Sei } & \multicolumn{2}{|c|}{ Não Resp. } \\
\hline & $\underline{\mathrm{n}}$ & $\%$ & $\underline{\mathrm{n}}$ & $\%$ & $\underline{\mathrm{n}}$ & $\%$ & $\underline{\mathrm{n}}$ & $\%$ \\
\hline $\begin{array}{l}\text { 18. Ter múltiplos parceiros sexuais e } \\
\text { não usar a camisinha }\end{array}$ & 132 & 96,4 & - & - & - & - & 5 & 3,6 \\
\hline $\begin{array}{l}\text { 19. Ter relação sexual vaginal com } \\
\text { uma pessoa que é portadora do HIV } \\
\text { sem usar a camisinha }\end{array}$ & 135 & 99,5 & - & - & - & - & 2 & 1,5 \\
\hline $\begin{array}{l}\text { 20. Ter relação sexual anal com uma } \\
\text { pessoa que é portadora do HIV sem } \\
\text { usar a camisinha }\end{array}$ & 133 & 97,3 & - & - & 1 & 0,6 & 3 & 2,1 \\
\hline $\begin{array}{l}\text { 21. Ter relação sexual oral com uma } \\
\text { pessoa que é portadora do HIV sem } \\
\text { usar a camisinha }\end{array}$ & 124 & 90,5 & 7 & 5,0 & 4 & 3,0 & 2 & 1,5 \\
\hline
\end{tabular}

Fonte: dados da pesquisa.

Nas questôes relacionadas ao comportamento das pessoas perante a AIDS, houve um índice de manifestação de comportamento positivo de aproximadamente $80 \%$. Contudo algumas questôes merecem ser ressaltadas como: $51 \%$ acreditam que podem ser contaminados doando sangue; $29,2 \%$ dos universitários creem que a contaminação pode ocorrer ao beijar na boca uma pessoa que é portadora do HIV; 11,1\% afirmaram ser provável contaminar-se com o HIV ao se utilizarem banheiros públicos; e 8,7\%, ao ser picado por um mosquito ou outros insetos.

Esses dados fazem com que novamente as campanhas preventivas sejam questionadas, ou seja, até que ponto elas estão bem orientadas, uma vez que é amplamente difundida a informação de que o vírus da AIDS não se propaga pelo ar, por contatos casuais do convívio social diário, por picadas de insetos ou mordidas de animais. Isto é, para que aconteça a contaminação, é necessário que ocorram trocas de fluidos corporais e por meio do uso de agulhas e seringas contaminadas (Papalia \& Olds, 2000). É de se admirar que universitários com acesso a todo e qualquer tipo de informação relatem respostas desse cunho.

Os estudantes de Fonoaudiologia da UCDB apresentam, no geral, um nível de conhecimento em relação à AIDS consideravelmente alto, de 75,3\%, ou seja, um índice de $78 \%$ no que diz respeito à identidade do HIV, um total de $68,1 \%$ referente às medidas preventivas da transmissão sexual e $80 \%$ no que se relaciona aos meios de transmissão do HIV. Dessa forma, demonstram um entendimento incompleto apenas quanto aos métodos de prevenção. Já no estudo de Hallack Neto et alii (1996), os universitários parecem ter um 
conhecimento teórico correto sobre as medidas preventivas contra a AIDS e entendimento insuficiente sobre a transmissão do HIV. Provavelmente essas dúvidas podem estar interferindo diretamente no comportamento desses sujeitos, fazendo com que apresentem atitudes negativas e que não percebam o risco de adquirirem o vírus.

\section{Atitude e percepção de risco}

A tabela 4 apresenta os resultados referentes às atitudes e percepção de risco dos participantes da pesquisa. As categorias de respostas "definitivamente verdadeira" e "provavelmente verdadeira" foram agrupadas em "verdadeira". O mesmo foi feito com as categorias "provavelmente falso" e "definitivamente falso", que foram agrupadas como somente "falsa".

Tabela 4 - Atitudes e percepção de risco revelada pelos acadêmicos

\begin{tabular}{lllll}
\hline Questões/categoria das respostas & Verdadeira & Falsa & Não Sei & $\begin{array}{l}\text { Não } \\
\text { Resp. }\end{array}$
\end{tabular}

\begin{tabular}{|c|c|c|c|c|c|c|c|c|}
\hline & $\mathrm{n}$ & $\%$ & $\mathrm{n}$ & $\%$ & $\underline{\mathrm{n}}$ & $\%$ & $\underline{\mathrm{n}}$ & $\%$ \\
\hline 1. Eu corro risco de pegar AIDS & 42 & 30,8 & 75 & 54,8 & 17 & 12,2 & 3 & 2,2 \\
\hline $\begin{array}{l}\text { 2. Eu acho que estão se preocupando } \\
\text { com a AIDS mais do que deviam }\end{array}$ & 12 & 8,0 & 118 & 86,8 & 3 & 2,2 & 4 & 3,0 \\
\hline $\begin{array}{l}\text { 3. Eu acredito nas informações que o } \\
\text { governo fornece sobre a AIDS }\end{array}$ & 98 & 71,8 & 23 & 16,8 & 6 & 4,4 & - & - \\
\hline 4. Eu não teria nenhum problema em & 76 & 55,5 & 47 & 34,3 & 10 & 7,2 & 4 & 3,0 \\
\hline
\end{tabular}
me relacionar profissionalmente com um companheiro(a) de uma pessoa com AIDS

5. Eu tenho medo de pegar AIDS no meu trabalho

6. Eu sei como me proteger da AIDS

7. Eu acredito que a AIDS é um castigo

8. Eu teria medo de trabalhar com alguém que tivesse AIDS

9. Eu não estou preocupado em pegar AIDS

$\begin{array}{llllllll}28 & 20,4 & 100 & 73,0 & 5 & 3,6 & 4 & 3,0\end{array}$

$\begin{array}{llllllll} & 709,8 & 21 & 15,1 & 5 & 3,6 & 2 & 1,5\end{array}$

$\begin{array}{llllllll}18 & 13,2 & 103 & 75,1 & 14 & 10,2 & 2 & 1,5\end{array}$

$\begin{array}{llllllll}26 & 19,0 & 98 & 71,6 & 10 & 7,2 & 3 & 2,2\end{array}$

$\begin{array}{llllllll}27 & 19,7 & 105 & 76,6 & 3 & 2,2 & 2 & 1,5\end{array}$

10. Quem tivesse AIDS deveria ser colocado num lugar isolado

$\begin{array}{llllllll}8 & 5,8 & 123 & 89,7 & 4 & 3,0 & 2 & 1,5\end{array}$

11. Se eu tivesse escolha, eu preferiria não trabalhar com AIDS

$\begin{array}{llllllll}39 & 28,5 & 75 & 54,9 & 21 & 15,1 & 2 & 1,5\end{array}$ 


\begin{tabular}{|c|c|c|c|c|c|c|c|c|}
\hline \multirow[t]{2}{*}{ Questões/categoria das respostas } & \multicolumn{2}{|c|}{ Verdadeira } & \multicolumn{2}{|c|}{ Falsa } & \multicolumn{2}{|c|}{ Não Sei } & \multicolumn{2}{|c|}{$\begin{array}{l}\text { Não } \\
\text { Resp. }\end{array}$} \\
\hline & $\mathrm{n}$ & $\%$ & $\mathrm{n}$ & $\%$ & $\underline{\mathrm{n}}$ & $\%$ & $\underline{\mathrm{n}}$ & $\%$ \\
\hline $\begin{array}{l}\text { 12. Só pega AIDS quem é promíscuo } \\
\text { e usuário de drogas }\end{array}$ & 16 & 11,5 & 114 & 83,3 & 4 & 3,0 & 3 & 2,2 \\
\hline $\begin{array}{l}\text { 13. Eu me sinto moralmente ofendi- } \\
\text { do pelas pessoas com AIDS }\end{array}$ & 4 & 3,0 & 125 & 91,2 & 5 & 3,6 & 3 & 2,2 \\
\hline $\begin{array}{l}\text { 14. Tenho treinamento profissional } \\
\text { necessário para prestar atendimento } \\
\text { a uma pessoa com AIDS }\end{array}$ & 21 & 15,1 & 100 & 73,0 & 12 & 8,9 & 4 & 3,0 \\
\hline $\begin{array}{l}\text { 15. O vírus da AIDS foi criado em } \\
\text { laboratório para exterminar os ho- } \\
\text { mossexuais }\end{array}$ & 4 & 3,0 & 106 & 77,4 & 20 & 14,6 & 7 & 5,0 \\
\hline $\begin{array}{l}\text { 16. As instituições governamentais } \\
\text { não estão informando tudo o que } \\
\text { sabem sobre a AIDS }\end{array}$ & 47 & 34,3 & 69 & 50,3 & 18 & 13,2 & 3 & 2,2 \\
\hline $\begin{array}{l}\text { 17. Eu sinto compaixão pelas pessoas } \\
\text { com AIDS }\end{array}$ & 81 & 59,1 & 39 & 28,5 & 11 & 8,0 & 6 & 4,4 \\
\hline $\begin{array}{l}\text { 18. Eu acho que os pacientes com } \\
\text { AIDS merecem estar doentes }\end{array}$ & 7 & 5,0 & 126 & 92,2 & 1 & 0,6 & 3 & 2,2 \\
\hline $\begin{array}{l}\text { 19. Eu penso que as pessoas com } \\
\text { AIDS não merecem ser tratadas com } \\
\text { compaixão. }\end{array}$ & 17 & 12,3 & 113 & 82,5 & 4 & 3,0 & 3 & 2,2 \\
\hline
\end{tabular}

Fonte: dados da pesquisa.

Com relação às questôes sobre as atitudes e a percepção de risco dos participantes perante a AIDS, podem-se encontrar respostas um pouco contraditórias, ou seja, 54,7\% dos alunos afirmaram não correr risco de contrair o vírus HIV e 19,7\% responderam que não estão preocupados em pegar AIDS. Contudo, 15,3\% afirmaram não saber se proteger contra a AIDS. Esses dados sinalizam que os acadêmicos têm percepção de risco negativa ou insuficiente para a doença.

Aproximadamente $34 \%$ dos alunos acreditam que as instituições governamentais não estão informando tudo o que sabem sobre a AIDS e ainda $16,8 \%$ dos participantes não acreditam nas informaçóes que o governo fornece sobre a doença.

Um número considerável de pessoas relata atitudes preconceituosas para com os portadores de HIV/AIDS, revelando que 34,3\% teriam problema em se relacionar profissionalmente com um companheiro de uma pessoa com AIDS; $28,4 \%$ dos participantes afirmam que, se tivessem escolha, prefeririam 
não trabalhar com AIDS, pois $73 \%$ relatam não ter treinamento profissional necessário para prestar atendimento a uma pessoa com AIDS.

As questôes que investigam o aspecto moral da doença são respondidas da seguinte maneira: $13,3 \%$ acreditam que a AIDS é um castigo, 5,8\% acham que as pessoas com AIDS deveriam ser colocadas num lugar isolado, 11,7\% são da opinião de que só pega AIDS quem é promíscuo e usuário de drogas, e ainda $28,5 \%$ confessam que não sentem compaixão pelos portadores do HIV.

Trinta e quatro pessoas, o que representa $24,8 \%$ dos participantes, relataram que receberam muitas informações sobre a AIDS, mas ainda estão muito confusas, $16,8 \%$ relataram não terem recebido informaçôes suficientes e gostariam de receber mais. Um total de 69 acadêmicos (50,4\%) revelaram que receberam informações suficientes e têm boa compreensão do problema.

Apesar de apresentarem um nível significativamente alto de conhecimento, o mesmo não acontece com as atitudes e percepção de risco dos estudantes, cujo índice é de $66,8 \%$. Pouco mais da metade da população $(54,7 \%)$ afirma não correr o risco de pegar AIDS, ou seja, demonstram percepção de risco relativamente baixa. Esses dados corroboram o estudo de Gir et alii (1999), o qual constatou que, mesmo bem informados acerca da AIDS, os universitários consideram pequena a probabilidade de contraí-la.

Esse estudo ainda ratifica a afirmação de McCornick (1997) de que o conhecimento, por si só, não faz com que as pessoas tenham atitudes favoráveis ou apresentem comportamento positivo diante da AIDS, ou mesmo perante determinadas situações. Partindo desse princípio, torna-se relevante a preocupação de inúmeros pesquisadores em estudar o comportamento, atitudes, entre outros fatores que implicam açôes e pensamentos das pessoas em detrimento de determinadas situaçóes. Hallack Neto et alii (1996), Toledo Júnior et alii (1999) e Bento (1999), entre outros, abordam a necessidade de se instituírem programas, medidas preventivas e estratégicas direcionadas à informação, ao esclarecimento e ao desenvolvimento de habilidades que atuem diretamente na mudança de comportamento e de atitudes.

\section{Considerações finais}

Entramos na terceira década de convivência com a epidemia da AIDS.

O Brasil encontra-se em sexto lugar no mundo em relação ao número de 
pessoas infectadas pelo HIV, sendo o país com o maior número de casos na América Latina, segundo dados da Fnuap/Unaids (2005).

Desde a descoberta do HIV, no início da década de 1980, o número de casos notificados e estimados não para de aumentar no Brasil e no mundo, de uma forma geral. Esse fato mobiliza as secretarias de Estados e Municípios, o Ministério da Saúde, organizações não governamentais (ONGs), enfim, inúmeras entidades que se preocupam com a expansão da epidemia.

Assim, coletivamente, a epidemia se impõe como um problema que exige respostas de diferentes setores governamentais e não governamentais, e demanda mobilização para que recursos sejam garantidos e aplicados na prevenção e assistência para que a discriminação e o preconceito sejam minimizados.

Em virtude do aumento preocupante de casos é que se instituem pesquisas dos mais diversos cunhos, visando a clarificar formas de atuação preventiva, pois conhecer o perfil e características peculiares de cada grupo populacional é importante para a realização das propostas.

Assim, considerando que o conhecimento sobre HIV/AIDS é um fator importante para a prevenção da doença, um dos objetivos desta pesquisa vem ao encontro do que se tem pesquisado, ou seja, é extremamente necessário que se identifique o conhecimento que os mais diversos segmentos da população têm sobre a AIDS para que sejam fomentadas estratégias de atuação, visando à prevenção.

Estratégias bem articuladas e desenvolvidas considerando o conhecimento da população certamente repercutirão na diminuição de casos de HIV/ AIDS, na percepção de risco positiva ou satisfatória, bem como em atitudes positivas perante a doença e os portadores de HIV/AIDS. Este estudo, ou seja, os resultados revelam que os universitários têm algumas atitudes negativas no atendimento de portadores do HIV/AIDS, fato que poderá repercutir na sua forma de atender essas pessoas. A maioria afirmou não correr risco de pegar a AIDS e relataram ainda que se sentem despreparados para intervir na problemática em questão, necessitando de maior capacitação profissional.

Como ainda não há vacina anti-HIV, o Brasil, além de ser reconhecido como exemplo de controle da epidemia com o uso de medicamentos graças à política brasileira de medicamentos, deve também ser reconhecido na questão da eficácia dos programas de prevenção e assistência a pessoas vivendo com HIV/AIDS. 
Em suma, a questão de se implantarem medidas preventivas e estratégicas eficazes que atuem diretamente no conhecimento, comportamento e atitudes das pessoas perante a AIDS apresenta-se de extrema importância, principalmente nas instituições formadoras de opinião e de futuros profissionais como são as universidades.

\section{Referências}

Almeida, A. D. L.; Silva, C. F. \& Cunha, G. S. (2007). Os conhecimentos, atitudes e comportamentos sobre SIDA dos adolescentes portugueses do meio urbano e não urbano. Revista da Escola de Enfermagem da USP, 41 (2), 180-186.

Andrade, S. M. O. \& Tanaka, O. Y. O. (2002). Saber e a prevenção no trabalho e na vida: representaçôes de profissionais de saúde que trabalham com HIV/AIDS. Psicologia: Ciência e Profissão, 22 (2), 60-69.

Bento, I. (1999). Sexualidade e DST/AIDS em uma população universitária. DST Jornal Brasileiro de Doenças Sexualmente Transmissiveis, 11 (2), 17-25.

Brasil. Ministério da Saúde. (2009). Secretaria de Vigilância em Saúde Programa Nacional de DST/AIDS. Boletim Epidemiológico - AIDS e DST, Brasília, 6 (1), 1- 62.

Camargo, B. V. \& Botelho, L. J. (2007). AIDS, sexualidade e atitudes de adolescentes sobre a proteção contra o HIV. Revista de Saúde Pública, 41 (1), 61-68.

Camargo, E. A. I. \& Ferrari, R. A. P. (2009). Adolescentes: conhecimento sobre sexualidade antes e após a participação em oficinas de prevenção. Ciência e Saúde Coletiva, 14 (3), 937-946.

Diclemente, R. J.; Zorn, J; Temoshok, L. (1986). Adolescents and AIDS: a survey of knowledge, attitudes and beliefs about AIDS in San Francisco. American Journal of Public Health, 76 (12), 1443-1445.

Fnuap; Unaids. (2005). Dados sobre AIDS. Recuperado em 17 de novembro, 2005, de http://www.unaids.org/hivaidsinfo/index.html.

Gimenez et alii. (1996). A prevenção da AIDS entre estudantes universitários: a resposta da Ufscar. Sociedade Brasileira de Psicologia, 1 (1), 59-70. 
Gir, E. et alii. (1999). Medidas preventivas contra a AIDS e outras doenças sexualmente transmissíveis conhecidas por universitários da área da saúde. Revista Latino-Americana de Enfermagem, 7(1), 11-17.

Hallack Neto, A. E. et alii. (1996). Pesquisa sobre conhecimentos e atitudes do estudante universitário diante da SIDA. HU Revista, 22 (2), 23-35.

Madureira, V. S. F. \& Trentini, M. (2008). Da utilização do preservativo masculino à prevenção de DST/AIDS. Ciência e Saúde Coletiva, 13 (6), 1807-1816.

Martins et alii. (2006). Fatores associados ao uso de preservativo masculino e ao conhecimento sobre DST/AIDS em adolescentes de escolas públicas e privadas do Município de São Paulo, Brasil. Caderno de Saúde Pública, 22 (2), 315-323.

McCornick, A. S. (1997). Revisiting college student knowledge and attitudes about HIV/AIDS: 1978, 1991 e 1995. College Student Journal, 31 (3), 356365.

Owens, S. (1995). Attitudes toward and knowledge of AIDS among social work students. Health and Social Work, 20 (2), 110-121.

Papalia, D. E. \& Olds, S. W. (2000). Desenvolvimento humano. Porto Alegre: Artes Médicas.

Rodrigues, A. (2005). Psicologia social para principiantes: estudo da interação humana. (10a ed.). Petrópolis: Vozes.

Toledo Júnior, A. C. C. et alii. (1999). Conhecimento, atitudes e comportamentos perante o risco ocupacional de exposição ao HIV entre estudantes de Medicina da Faculdade de Medicina da Universidade Federal de Minas Gerais. Revista da Sociedade Brasileira de Medicina Tropical, 32 (5), 509-515. 